\title{
Produtividade de sistemas forrageiros consorciados com leguminosas
}

\author{
[Productivity of grazing systems mixed with forage legumes] \\ M.S. Diehl ${ }^{1}$, C.J. Olivo $^{2}$, C.A. Agnolin ${ }^{1}$, V.F. Bratz ${ }^{3}$, C.M. Bem ${ }^{1}$, P.F. Agüirre ${ }^{1}$, \\ C.L. Glienke ${ }^{1}$, M.R. Correa ${ }^{3}$, G. Serafim ${ }^{3}$ \\ ${ }^{1}$ Aluna de pós-graduação - Universidade Federal de Santa Maria - UFSM - Santa Maria, RS \\ ${ }^{2}$ Universidade Federal de Santa Maria - UFSM - Santa Maria, RS \\ ${ }^{3}$ Aluno(a) de graduação - Universidade Federal de Santa Maria - UFSM - Santa Maria, RS
}

\begin{abstract}
RESUMO
O objetivo desta pesquisa foi avaliar três sistemas forrageiros (SF) com capim elefante (CE) + azevém $(\mathrm{AZ})+$ espécies de crescimento espontâneo (ECE); $\mathrm{CE}+\mathrm{AZ}+\mathrm{ECE}+$ amendoim forrageiro (AM); e CE $+\mathrm{AZ}+\mathrm{ECE}+$ trevo vermelho (TV), usando-se a mesma área, sob pastejo rotacionado, no decorrer do ano agrícola. O CE foi estabelecido em linhas afastadas a cada $4 \mathrm{~m}$. No período hibernal, fez-se o estabelecimento do AZ entre as linhas do CE; o TV foi semeado e o AM foi preservado, considerando-se os respectivos SF. O delineamento experimental foi o inteiramente ao acaso, com três tratamentos (SF), duas repetições (piquetes) e avaliações independentes (ciclos de pastejos). Para avaliação, foram utilizadas vacas da raça Holandesa em lactação, que receberam suplementação alimentar com concentrado à razão de $1 \%$ do peso corporal/dia. Foram avaliados a massa de forragem, os componentes botânicos do pasto e estruturais do CE e a taxa de lotação. Durante o período experimental, foram efetuados oito ciclos de pastejo. Sistemas forrageiros que envolvem gramíneas e leguminosas de diferentes ciclos proporcionam a utilização da área durante todo o ano agrícola em pastejo rotativo com bovinos leiteiros. Considerando-se a predominância das avaliações em cada pastejo, os sistemas forrageiros consorciados apresentam melhor resultado tanto paras as variáveis de massa de forragem quanto para a taxa de lotação.
\end{abstract}

Palavras-chave: Arachis pintoi, pastejo rotacionado, Pennisetum purpureum, Trifolium pratense, vacas leiteiras

\begin{abstract}
The objective of this research was to evaluate three grazing systems $(G S)$ with elephant grass $(E G)+$ ryegrass $(R G)+$ spontaneous growing species $(S G S) ; E G+R G+S G S+$ forage peanut $(F P)$; and $E G+$ $R G+S G S+$ red clover $(R C)$, in order to use the area in rotational grazing during the agricultural year. $E G$ was planted in rows with a distance of $4 m$ between each row. In the cool-season, $R G$ was sowed between EG rows and FP was preserved on GS. The experimental design was completely randomized with three treatments (GS), two replicates (paddocks) and independent evaluations (grazing cycles). For the evaluation lactating Holstein cows receiving $1 \%$ of BW/day feed supplement concentrate were used. The herbage mass, botanical composition of pasture, structural component of EG and stocking rate were evaluated. Eight grazing cycles were performed during the experimental period. Grazing systems involving grass and legume forage in different cycles provided the use of the area during the agricultural year in rotational grazing with dairy cattle. Considering the predominance of the evaluations in each grazing, the mixed grazing systems have better results for both forage mass and stocking rate variables.
\end{abstract}

Keywords: Arachis pintoi; Lactating Cows; Pennisetum purpureum; Rotational Grazing; Trifolium pratense

Recebido em 9 de março de 2012

Aceito em 12 de março de 2013

E-mail: miche_diehl@hotmail.com 


\section{INTRODUÇÃO}

$\mathrm{Na}$ maior parte das propriedades leiteiras do Rio Grande do Sul, as pastagens, principalmente as gramíneas, são a principal fonte de volumoso para os bovinos. Os sistemas de produção, tendo como base as pastagens, são os mais viáveis em propriedades leiteiras que, normalmente, apresentam poucos recursos para investimento (Rocha et al., 2007).

Entre as plantas forrageiras, o capim elefante (Pennisetum purpureum Schum.) é uma forrageira importante nas propriedades leiteiras, especialmente por sua perenidade, pela possibilidade de uso em áreas declivosas e por apresentar elevada produção de massa de forragem. Seu uso tem se intensificado sob a forma de pastagem, implicando a melhoria do volumoso ofertado e a redução de mão de obra em comparação à sua utilização como capineira.

Por outra parte, a sustentabilidade dos sistemas pastoris pode ser melhorada com a utilização de leguminosas em consórcio com gramíneas (Shonieski et al., 2011). Pesquisas comprovam que o uso de leguminosas em consórcio com gramíneas pode reduzir os gastos diretos com fertilizantes; aumentar a qualidade e a diversificação da dieta consumida pelos animais; melhorar a disponibilidade de forragem pelo aporte de nitrogênio ao sistema por meio de sua reciclagem e transferência para a gramínea consorciada e aumentar também o período de utilização das pastagens (Barcellos et al., 2008).

Espécies como azevém (Lolium multiflorum Lam.), amendoim forrageiro (Arachis pintoi Krap. e Greg.) e trevo vermelho (Trifolium repens L.), por possuírem alto valor nutritivo e boa capacidade de adaptação, podem ser importantes na consorciação com capim elefante (Assis et al., 2008; Olivo et al., 2009), visando ao uso da mesma área durante o ano agrícola.

Assim, esta pesquisa tem como objetivo avaliar três sistemas forrageiros, constituídos por capim elefante, azevém e duas leguminosas (amendoim forrageiro ou trevo vermelho), quanto à massa de forragem e à taxa de lotação, com o intuito de utilização da área durante todo o ano agrícola em pastejo rotativo com bovinos leiteiros.

\section{MATERIAL E MÉTODOS}

Todas as técnicas e os procedimentos utilizados no presente estudo foram aprovados pelo Comitê de Ética em Experimentação Animal da Universidade Federal de Santa Maria (protocolo $\mathrm{n}^{\mathrm{o}} 23081016073 / 2011-27$, parecer 113/2011).

O experimento foi conduzido em Santa Maria, em área pertencente ao Departamento de Zootecnia da Universidade Federal de Santa Maria, situada na região da Depressão Central, com altitude de $95 \mathrm{~m}$ acima do nível do mar, latitude $29^{\circ} 43^{\prime}$ Sul e longitude $53^{\circ} 42^{\prime}$ Oeste, em solo classificado como Argissolo Vermelho Eutrófico (Embrapa, 2006), no período de 27/05/10 a 11/04/11.

O clima da região é o Cfa (subtropical úmido), segundo a classificação de Köppen (Moreno, 1961). As médias climáticas anuais de temperatura do ar e precipitação pluviométrica são de $19,6^{\circ} \mathrm{C}$ e $140,5 \mathrm{~mm}$, respectivamente. No período experimental, as médias foram de $18,1^{\circ} \mathrm{C}$ e $182,1 \mathrm{~mm}$, respectivamente. Destaca-se que, para precipitação pluviométrica, houve excedente nos meses de julho, setembro e novembro, e déficits em outubro, dezembro e março. Durante os meses de junho, julho e agosto foram registradas três, seis e seis geadas, respectivamente. Os dados foram coletados na Estação Experimental Meteorológica da UFSM, situada a $500 \mathrm{~m}$ da área experimental, aproximadamente.

Foram avaliados três tratamentos (sistemas forrageiros), constituídos por capim elefante (Pennisetum purpureum Schum.), cv. Merckeron Pinda; azevém (Lolium multiflorum Lam.), cv. Comum e espécies de crescimento espontâneo; os demais foram constituídos pelos consórcios, sendo um com amendoim forrageiro (Arachis pintoi Krap. e Greg.), cv. Amarillo e o outro com trevo vermelho (Trifolium pratense L.), cv. Estanzuela 116.

Foram utilizados para a adubação $150 \mathrm{~kg} / \mathrm{ha}$ de N-P-K (5-20-20), 60 e 50kg/ha de $\mathrm{P}_{2} \mathrm{O}_{5}$ e $\mathrm{K}_{2} \mathrm{O}$, respectivamente, divididos em duas aplicações, sendo a primeira no estabelecimento do azevém e a segunda na metade do mês de outubro de 2010. A recomendação de adubação teve como base o consórcio gramínea leguminosa, utilizando-se um valor médio da recomendação 
para os períodos hibernal e estival (Comissão de Química e Fertilidade do Solo - RS/SC, 2004). Como adubação nitrogenada, utilizaram-se $116 \mathrm{~kg} / \mathrm{ha}$, sob a forma de ureia, parcelada em cinco aplicações efetuadas nos meses de junho, agosto, outubro, novembro de 2010 e fevereiro de 2011.

O critério de utilização do pasto durante o período hibernal, da semeadura à utilização do azevém, entre maio e outubro, teve como base a altura do dossel, sendo que a entrada dos animais dava-se quando este se encontrava com $20 \mathrm{~cm}$ aproximadamente; no estival foi à altura do capim elefante, entre 100 e $120 \mathrm{~cm}$.

A área experimental utilizada foi de 0,78ha (subdividida em seis piquetes de 0,13 ha cada um) com capim elefante já estabelecido desde 2004, em linhas afastadas a cada 4m. No dia 13 de maio de 2010, foi realizada uma roçada para padronização da área entre as linhas formadas por touceiras de capim elefante, sendo, na sequência, semeado o azevém, mediante escarificação do solo, em toda área experimental, à razão de $30 \mathrm{~kg} / \mathrm{ha}$; para as pastagens consorciadas com leguminosas, fez-se a semeadura do trevo vermelho, à razão de $6 \mathrm{~kg} / \mathrm{ha}$, e preservou-se o amendoim forrageiro, estabelecido em 2006.

A massa de forragem de matéria seca foi estimada pela técnica de estimativa visual com dupla amostragem, conforme Wilm (1944), antes da entrada e após a saída dos animais da área. As amostragens foram feitas no alinhamento formado pelas touceiras de capim elefante e no espaço entre elas. No capim elefante, os cortes foram feitos a $50 \mathrm{~cm}$ do solo e entre as linhas de capim elefante, rente ao solo. A forragem proveniente das amostras cortadas foi homogeneizada e, após, uma subamostra composta por pastejo foi utilizada para a determinação das composições botânica do pasto e estrutural do capim elefante, sendo posteriormente seca em estufa para determinação do teor de matéria seca conforme Silva (1990).

Para estimativa da massa de forragem no período hibernal (da semeadura à utilização do azevém, de maio a outubro), considerou-se que $25,9 \%$ da área foi ocupada pelo capim elefante e $74,1 \%$ pelas espécies presentes entre as linhas do capim elefante. No período estival, consideraram-se $30,9 \%$ da área total ocupada pelo capim elefante e $69,1 \%$ pelo espaço entre as linhas de capim elefante. $O$ valor da massa de forragem obtido nas linhas de capim elefante e nas entrelinhas foi multiplicado pela porcentagem de ocupação da área, sendo somados para obtenção da massa de forragem do piquete.

A carga animal instantânea foi estimada da oferta de forragem de 4 e $6 \mathrm{~kg} \mathrm{MS} / 100 \mathrm{~kg}$ de peso corporal para a massa de forragem de lâminas foliares do capim elefante e para a massa de forragem do material presente nas entrelinhas, respectivamente. $\mathrm{O}$ método de pastejo foi $\mathrm{o}$ rotacionado, com um a dois dias de ocupação.

Foram utilizadas vacas em lactação da raça Holandesa, com peso corporal médio de $532 \mathrm{~kg}$ e produção média de leite de 18,07kg/dia. Os animais foram submetidos à ordenha mecânica duas vezes ao dia. Após as ordenhas, as vacas receberam suplementação alimentar de acordo com a produção de leite, sendo fornecido, em média, $0,9 \%$ do PC/dia. O concentrado apresentava $70 \%$ de NDT e $20 \%$ de PB.

O delineamento experimental utilizado foi $\mathrm{o}$ inteiramente casualizado, com três tratamentos (sistemas forrageiros), duas repetições de área (piquetes) e avaliações independentes (ciclos de pastejo). Os dados foram submetidos à análise de variância, e as médias comparadas pelo teste de Tukey, ao nível de 5\% de probabilidade do erro. As análises foram efetuadas com auxílio do pacote estatístico SAS (Statistical..., 2001).

O modelo estatístico referente à análise das variáveis estudadas da pastagem foi representado por: $Y_{i j k}=m+T_{i}+\varepsilon_{i j k}$, em que: $Y_{i j k}$ representa as variáveis dependentes; i, o índice de tratamentos (sistemas forrageiros); $\mathrm{j}$, o índice de repetições (piquetes); k, o índice de pastejos; m, a média de todas as observações; $\mathrm{T}_{\mathrm{i}}$, $\mathrm{o}$ efeito dos tratamentos; e $\varepsilon_{\mathrm{ijk}}$, o erro experimental residual.

\section{RESULTADOS E DISCUSSÃO}

No período de avaliação, entre julho e abril (357 dias), foram realizados oito ciclos de pastejo nos sistemas forrageiros. Os ciclos de pastejo variaram de 43 e 39 dias, nos períodos hibernal e estival, respectivamente. 
Quanto à massa de forragem de pré-pastejo, houve similaridade entre os sistemas forrageiros (Tab. 1), havendo diferença $(\mathrm{P} \leq 0,05)$ apenas nas avaliações efetuadas em fevereiro, março e abril, com valores superiores para os sistemas constituídos por leguminosas. O valor médio de massa de forragem para os sistemas foi de $3,09 \mathrm{t} / \mathrm{ha}$, sendo inferior ao verificado por Azevedo Júnior (2011), de 3,5t/ha, ao utilizar sistemas similares, mas com maior quantidade de fertilizante nitrogenado.

Tabela 1. Massa de forragem de pré-pastejo, dos componentes botânicos e estruturais (kg de matéria seca/ha) e taxa de lotação, de três sistemas forrageiros (SF). Santa Maria, RS

\begin{tabular}{|c|c|c|c|c|c|c|c|c|c|c|}
\hline \multirow{3}{*}{ SF } & \multicolumn{8}{|c|}{ Pastejos } & \multirow{3}{*}{ Média } & \multirow{3}{*}{$\begin{array}{l}\mathrm{CV} \\
(\%)\end{array}$} \\
\hline & $1^{\circ}$ & $2^{\circ}$ & $3^{\circ}$ & $4^{\circ}$ & $5^{\circ}$ & $6^{\circ}$ & $7^{\circ}$ & $8^{\circ}$ & & \\
\hline & $\mathrm{Jul} / 10$ & Set/10 & Out/10 & Dez/10 & Jan/11 & $\mathrm{Fev} / 11$ & Mar/11 & Abri/11 & & \\
\hline \multicolumn{11}{|c|}{ Massa de forragem do pasto } \\
\hline $\mathrm{SL}^{1}$ & 2398 & 2779 & 1953 & 2088 & 3472 & $3378 b$ & $3843 b$ & $3514 b$ & 2928 & \multirow{3}{*}{3,86} \\
\hline $\mathrm{AM}^{2}$ & 2485 & 3025 & 1980 & 2293 & 3012 & $3685 b$ & $3756 b$ & $3484 b$ & 2965 & \\
\hline $\mathrm{TV}^{3}$ & 2674 & 3068 & 1747 & 2243 & 2668 & $4424 a$ & $4136 a$ & $4214 a$ & 3147 & \\
\hline \multicolumn{11}{|c|}{ Lâmina foliar de capim elefante } \\
\hline SL & 492 & 548 & $*$ & 475 & 753 & 695 & $774 b$ & 643 & 626 & \multirow{3}{*}{5,26} \\
\hline $\mathrm{AM}$ & 681 & 785 & $*$ & 345 & 878 & 799 & $833 b$ & 729 & 721 & \\
\hline TV & 666 & 717 & $*$ & 353 & 511 & 790 & $1041 \mathrm{a}$ & 681 & 680 & \\
\hline \multicolumn{11}{|c|}{ Colmo + bainha de capim elefante } \\
\hline SL & 498 & 624 & $*$ & 93 & $238 \mathrm{a}$ & $188 b$ & 309 & 378 & 333 & \multirow{3}{*}{12,36} \\
\hline $\mathrm{AM}$ & 533 & 721 & $*$ & 59 & $130 \mathrm{a}$ & $261 \mathrm{a}$ & 335 & 257 & 328 & \\
\hline TV & 558 & 645 & $*$ & 58 & $63 b$ & $275 a$ & 346 & 326 & 324 & \\
\hline \multicolumn{11}{|c|}{ Material morto de capim elefante } \\
\hline SL & 238 & 171 & $*$ & 27 & 7 & 0,4 & 0,3 & 47 & 70 & \multirow{3}{*}{16,51} \\
\hline $\mathrm{AM}$ & 245 & 175 & $*$ & 42 & 5 & 0,2 & 0,2 & 36 & 72 & \\
\hline TV & 269 & 302 & $*$ & 45 & 6 & 0,2 & 0,2 & 47 & 96 & \\
\hline \multicolumn{11}{|c|}{ Azevém } \\
\hline SL & 610 & $1162 \mathrm{a}$ & $1527 \mathrm{a}$ & - & - & - & - & - & 1100 & \multirow{3}{*}{5,07} \\
\hline $\mathrm{AM}$ & 563 & $761 b$ & $1024 b$ & - & - & - & - & - & 783 & \\
\hline TV & 555 & $924 b$ & $975 b$ & - & - & - & - & - & 818 & \\
\hline \multicolumn{11}{|c|}{ Espécies de crescimento espontâneo } \\
\hline SL & 221 & 145 & 83 & $790 \mathrm{a}$ & $2304 a$ & $2494 a$ & $2759 a$ & $2445 b$ & 1405 & \multirow{3}{*}{13,71} \\
\hline $\mathrm{AM}$ & 142 & 113 & 83 & $504 b$ & $588 b$ & $852 b$ & $1388 b$ & $1187 \mathrm{c}$ & 607 & \\
\hline TV & 114 & 114 & 78 & $289 \mathrm{c}$ & $459 b$ & $1933 \mathrm{ab}$ & $2748 \mathrm{a}$ & $3159 \mathrm{a}$ & 1112 & \\
\hline \multicolumn{11}{|c|}{ Leguminosas } \\
\hline $\mathrm{AM}$ & $106 b$ & 388 & 574 & $576 b$ & 1356 & 1773 & 1199 & 1275 & 906 & \multirow{2}{*}{12,90} \\
\hline TV & $340 \mathrm{a}$ & 269 & 495 & $1215 \mathrm{a}$ & 1553 & 1425 & - & - & 883 & \\
\hline \multicolumn{11}{|c|}{ Material morto da entrelinha } \\
\hline SL & 339 & 129 & 343 & 703 & $170 \mathrm{a}$ & 0,4 & 1,0 & 0,8 & 211 & \multirow{3}{*}{15,58} \\
\hline $\mathrm{AM}$ & 215 & 82 & 299 & 767 & $55 \mathrm{~b}$ & 0,2 & 0,4 & 0,2 & 177 & \\
\hline TV & 172 & 97 & 199 & 283 & $76 \mathrm{ab}$ & 0,3 & 0,7 & 0,9 & 104 & \\
\hline \multicolumn{11}{|c|}{ Taxa de lotação (UA/ha) } \\
\hline SL & 1,57 & 2,09 & 1,81 & 1,10 & 4,45 & $4,68 b$ & 5,38 & $4,07 \mathrm{~b}$ & 3,14 & \multirow{3}{*}{17,63} \\
\hline $\mathrm{AM}$ & 1,69 & 2,33 & 1,83 & 1,18 & 4,09 & $5,06 \mathrm{~b}$ & 5,26 & $4,25 b$ & 3,21 & \\
\hline TV & 1,79 & 2,30 & 1,62 & 1,16 & 4,52 & $6,00 \mathrm{a}$ & 5,91 & $5,00 \mathrm{a}$ & 3,41 & \\
\hline
\end{tabular}

${ }^{1} \mathrm{SL}=($ sem leguminosa) capim elefante $(\mathrm{CE})+$ azevém (AZE) + espécies de crescimento espontâneo (ECE), sem leguminosa; ${ }^{2} \mathrm{AM}=$ (consórcio com amendoim forrageiro) $\mathrm{CE}+\mathrm{AZE}+\mathrm{ECE}+$ amendoim forrageiro; ${ }^{3} \mathrm{TV}=$ (consórcio com trevo vermelho) $\mathrm{CE}+\mathrm{AZE}+\mathrm{ECE}+$ trevo vermelho; *roçada das linhas constituídas pelas touceiras de capim elefante; - ausência do componente; UA=unidade animal, (450kg de peso corporal). Médias seguidas por letras distintas, na coluna, diferem entre si $(\mathrm{P} \leq 0,05)$. $\mathrm{CV}=$ coeficiente de variação. 
Para a massa de lâminas foliares do capim elefante de pré-pastejo, houve similaridade entre os sistemas, destacando-se que os valores observados até o pastejo conduzido em setembro, embora baixos, demonstraram que essa forrageira contribuiu ao disponibilizar forragem ao sistema em boa parte do período hibernal, bem como equilibrar a oferta de pasto e a dieta dos animais, pois o azevém tem baixo teor de fibra nos pastejos iniciais. $\mathrm{O}$ valor médio da massa de lâminas foliares do capim elefante, de $0,67 \mathrm{t} / \mathrm{ha}$ durante $\mathrm{o}$ ano, foi inferior à disponibilidade de $0,96 \mathrm{t} / \mathrm{ha}$ encontrada por Steinwandter et al. (2009), com manejo similar.

Para a massa de forragem de colmo mais bainha de capim elefante, houve diferença $(\mathrm{P}<0,05)$ nos pastejos efetuados em janeiro e fevereiro, com valores superiores no consórcio com amendoim forrageiro. Para lâmina foliar do capim elefante, houve diferença no consórcio com trevo vermelho no pastejo realizado em março. Essas diferenças devem-se, possivelmente, ao efeito das leguminosas ao contribuírem com $\mathrm{N}$ ao sistema, implicando melhores condições de desenvolvimento à gramínea acompanhante (Pereira, 2001).

Quanto à massa de forragem de azevém, as diferenças observadas $(\mathrm{P} \leq 0,05)$ nos pastejos conduzidos em setembro e outubro devem-se à presença das leguminosas que interferem no desenvolvimento da gramínea associada (azevém), resultado também verificado por Paulino et al. (2008).

Com relação à massa de forragem das espécies de crescimento espontâneo, os valores são baixos no período hibernal e elevados no estival, destacando-se o Paspalum conjugatum, com 78,$55 ; 76,19$ e $73,40 \%$, respectivamente, para os sistemas forrageiros sem leguminosa, com amendoim forrageiro e com trevo vermelho. As diferenças ocorridas entre os sistemas demonstram que a presença das leguminosas implica controle das espécies de crescimento espontâneo (Teodoro et al., 2010). No consórcio envolvendo trevo vermelho, observa-se que a ausência da leguminosa nos pastejos efetuados em março e abril implicou aumento das espécies de crescimento espontâneo, possivelmente também pela disponibilidade de nutrientes ao sistema (Pereira, 2001), o que favorecendo o desenvolvimento de espécies como o $P$. conjugatum.

Para as leguminosas, a participação foi similar entre os sistemas, destacando-se a presença do amendoim forrageiro em todos os pastejos. A participação média no pasto foi de $31,57 \%$ para o amendoim forrageiro e de $34,45 \%$ para o trevo vermelho, valores próximos das recomendações de 30\% (Thomas, 1992) e entre 12 e $23 \%$ (Cadish et al., 1994), respectivamente, consideradas adequadas à sustentabilidade do sistema forrageiro.

Com relação à taxa de lotação, verificou-se diferença $(\mathrm{P} \leq 0,05)$ somente nos ciclos de pastejo efetuados em fevereiro e em abril, com melhor resultado no consórcio com trevo vermelho. Esse resultado deve-se à massa de forragem de prépastejo, que foi maior $(\mathrm{P} \leq 0,05)$ nesses pastejos. Os resultados da taxa de lotação com similaridade entre os sistemas forrageiros também são referenciados em outras pesquisas (Olivo et al., 2009; Azevedo Júnior, 2011). As taxas de lotação média para os períodos hibernal e estival foram de 1,89 e 4,12UA/ha, respectivamente, sendo similares aos observados por Deresz (2001) e superiores aos verificados por Lima et al. (2004), ambos com pastagem de capim elefante sob cultivo estreme.

Para a taxa de desaparecimento de forragem (Tab. 2), observa-se que houve diferença $(\mathrm{P} \leq 0,05)$ no pastejo efetuado em junho, com melhor resultado no consórcio com amendoim forrageiro. Possivelmente, isso seja devido à degradação de parte da estrutura das plantas dessa leguminosa, tanto da parte aérea quanto da subterrânea, pelo efeito do frio e das geadas, liberando $\mathrm{N}$ para o sistema e melhorando as condições de fertilidade do solo para o azevém. Em fevereiro, verificaram-se maiores taxas para os consórcios, provavelmente pela contribuição das leguminosas às gramíneas acompanhantes (Paulino et al., 2008), como se observa nas espécies de crescimento espontâneo. 
Tabela 2. Taxa de desaparecimento de matéria seca do pasto (TXD, \%) e taxa de matéria seca desaparecida em relação ao peso corporal (\%) de três sistemas forrageiros (SF). Santa Maria, RS

\begin{tabular}{|c|c|c|c|c|c|c|c|c|c|c|}
\hline \multirow{3}{*}{ SF } & \multicolumn{8}{|c|}{ Pastejos } & \multirow{3}{*}{ Média } & \multirow{3}{*}{$\begin{array}{l}\mathrm{CV} \\
(\%)\end{array}$} \\
\hline & $1^{\circ}$ & $2^{\circ}$ & $3^{\circ}$ & $4^{\circ}$ & $5^{\circ}$ & $6^{\circ}$ & $7^{\circ}$ & $8^{\circ}$ & & \\
\hline & Jun/10 & Set/10 & Out/10 & Dez/10 & Jan/11 & Fev/11 & Mar/11 & Abr/11 & & \\
\hline & \multicolumn{10}{|c|}{ TXD do pasto } \\
\hline $\mathrm{SL}^{1}$ & $51,56 \mathrm{~b}$ & 66,03 & 50,74 & 55,18 & 53,58 & 53,46 & $26,07 b$ & 54,50 & 49,90 & \multirow{3}{*}{4,54} \\
\hline $\mathrm{AM}^{2}$ & $61,69 a$ & 66,98 & 52,88 & 59,85 & 58,11 & 52,68 & $52,65 a$ & 58,80 & 57,15 & \\
\hline $\mathrm{TV}^{3}$ & $47,37^{\mathrm{b}}$ & 66,34 & 48,71 & 59,37 & 52,79 & 54,10 & $54,90 \mathrm{a}$ & 53,22 & 54,62 & \\
\hline \multicolumn{11}{|c|}{ TXD de lâmina foliar do capim elefante } \\
\hline SL & 55,08 & 79,01 & - & 84,42 & 79,15 & 87,63 & 73,51 & $85,07 \mathrm{~b}$ & 78,22 & \multirow{3}{*}{2,17} \\
\hline AM & 54,63 & 85,22 & - & 80,87 & 84,28 & 75,59 & 81,63 & $93,00 \mathrm{a}$ & 79,64 & \\
\hline TV & 53,45 & 85,36 & - & 84,96 & 71,62 & 75,57 & 84,44 & $92,66 \mathrm{a}$ & 78,61 & \\
\hline \multicolumn{11}{|c|}{ TXD de colmo + bainha do capim elefante } \\
\hline SL & 23,90 & 57,69 & - & $13,98 b$ & $52,52 \mathrm{a}$ & $50,00 \mathrm{a}$ & 7,44 & $47,88 \mathrm{a}$ & 39,30 & \multirow{3}{*}{2,29} \\
\hline $\mathrm{AM}$ & 31,14 & 56,31 & - & $33,71 \mathrm{a}$ & $40,77 b$ & $14,95 b$ & 5,97 & $38,76 b$ & 35,02 & \\
\hline TV & 33,69 & 44,34 & - & $25,00 \mathrm{ab}$ & $50,31 \mathrm{a}$ & $12,71 b$ & 11,85 & $27,91 b$ & 30,21 & \\
\hline \multicolumn{11}{|c|}{ TXD do azevém } \\
\hline SL & $47,54 b$ & 59,72 & 51,80 & - & - & - & - & - & 53,80 & \multirow{3}{*}{3,00} \\
\hline $\mathrm{AM}$ & $67,14 \mathrm{a}$ & 68,46 & 41,89 & - & - & - & - & - & 56,56 & \\
\hline TV & $28,83 \mathrm{c}$ & 56,60 & 39,87 & - & - & - & - & - & 43,28 & \\
\hline \multicolumn{11}{|c|}{ TXD das espécies de crescimento espontâneo } \\
\hline SL & 65,16 & $74,48 \mathrm{a}$ & $12,05 b$ & $30,38 b$ & $43,97 \mathrm{a}$ & $43,95 \mathrm{a}$ & $31,17 b$ & $46,46 \mathrm{ab}$ & 40,98 & \multirow{3}{*}{7,15} \\
\hline AM & 69,72 & $51,33 b$ & $37,35 \mathrm{a}$ & $71,83 \mathrm{a}$ & $51,70 \mathrm{a}$ & $28,87 \mathrm{~b}$ & $47,33 \mathrm{a}$ & $50,88 \mathrm{a}$ & 48,61 & \\
\hline TV & 50,88 & $79,82 \mathrm{a}$ & $11,54 \mathrm{~b}$ & $50,17 \mathrm{ab}$ & $27,45 b$ & $52,46 a$ & $43,70 \mathrm{a}$ & $44,73 b$ & 46,74 & \\
\hline \multicolumn{11}{|c|}{ TXD das leguminosas } \\
\hline $\mathrm{AM}$ & $42,25 b$ & $34,54 \mathrm{~b}$ & 75,26 & $26,91 b$ & 41,96 & 52,68 & 36,11 & 44,78 & 45,16 & \multirow{2}{*}{3,72} \\
\hline TV & $70,29 \mathrm{a}$ & $58,36 \mathrm{a}$ & 73,13 & $61,91 \mathrm{a}$ & 40,82 & 44,42 & - & - & 34,29 & \\
\hline \multicolumn{11}{|c|}{ Taxa de matéria seca desaparecida em \% do peso corporal } \\
\hline SL & 2,69 & 3,48 & 3,04 & 2,95 & 2,88 & 2,89 & 2,89 & $1,41 b$ & 2,79 & \multirow{3}{*}{15,88} \\
\hline $\mathrm{AM}$ & 3,09 & 3,39 & 3,17 & 3,33 & 3,10 & 3,10 & 2,87 & $3,46 a$ & 3,20 & \\
\hline TV & 2,41 & 3,40 & 2,92 & 3,30 & 2,88 & 2,88 & 2,96 & $2,90 \mathrm{a}$ & 2,96 & \\
\hline
\end{tabular}

${ }^{1} \mathrm{SL}=($ sem leguminosa) capim elefante $(\mathrm{CE})+$ azevém (AZE) + espécies de crescimento espontâneo (ECE), sem leguminosa; ${ }^{2} \mathrm{AM}=($ consórcio com amendoim forrageiro $) \mathrm{CE}+\mathrm{AZE}+\mathrm{ECE}+$ amendoim forrageiro; ${ }^{3} \mathrm{TV}=($ consórcio com trevo vermelho) $\mathrm{CE}+\mathrm{AZE}+\mathrm{ECE}+$ trevo vermelho; *roçada das linhas constituídas pelas touceiras de capim elefante; - ausência do componente. Médias seguidas por letras distintas, na coluna, diferem entre si $(\mathrm{P} \leq 0,05)$. $\mathrm{CV}=$ coeficiente de variação.

Para taxa de desaparecimento de lâminas foliares do capim elefante, houve diferença $(\mathrm{P} \leq 0,05)$ somente no pastejo conduzido em abril, com valor maior para os consórcios. Observa-se que as taxas são elevadas também no período hibernal, sendo indício de que essa forrageira apresenta elevado valor nutritivo nessa época (Azevedo Júnior, 2011) embora a sua baixa produção de forragem. Quanto ao azevém, a taxa média foi de $51,21 \%$, sendo similar à verificada por Steinwandter et al. (2009). A diferença ocorrida no pastejo feito em junho, com maior valor no consórcio com amendoim forrageiro, pode estar associada ao efeito residual da leguminosa, como observado por Azevedo Júnior
(2011). Para as leguminosas, os valores médios são considerados baixos, o que denota menor preferência dos animais em relação às gramíneas (Silva, 2008).

Com relação à taxa de matéria seca desaparecida com base no peso corporal, os valores médios ficaram próximos a $3 \%$ do peso corporal, considerando-se a suplementação alimentar que os animais receberam; bem como as perdas de forragem devido ao pastejo; ao acúmulo dos dejetos no período hibernal e às maiores perdas de forragem verificadas nessa época. 
Para a produção de forragem (Tab. 3), a menor produção $(\mathrm{P} \leq 0,05)$ dos consórcios, em janeiro, deve-se à menor contribuição da forragem nas entrelinhas, em parte pela elevada participação das leguminosas que interferem no desenvolvimento das gramíneas associadas (Paim, 1994). Em abril, houve melhor desempenho dos consórcios, apontando para um possível efeito residual de forragem. Esse resultado é importante, ao indicar melhor desempenho dos consórcios em um período em que há escassez de forragem (Restle et al., 2002). Considerando-se a produção de forragem no período experimental, com base na predominância dos resultados, confirma-se o melhor desempenho $(\mathrm{P} \leq 0,05)$ para os consórcios com leguminosas, resultado confirmado também por outros autores (Steinwandter et al., 2009; Azevedo Júnior, 2010). Observa-se que, para a composição estrutural do capim elefante, não houve diferença entre os sistemas forrageiros. Para as espécies presentes nas entrelinhas, ocorreram diferenças nas pastejos efetuados em janeiro e abril, com maior valor $(\mathrm{P} \leq 0,05)$ no sistema sem leguminosas.

Tabela 3. Produção de forragem do pasto (t/ha), das espécies presentes entre as linhas constituídas por CE e dos componentes estruturais do CE de três sistemas forrageiros (SF). Santa Maria, RS

\begin{tabular}{|c|c|c|c|c|c|c|c|c|c|c|c|}
\hline \multirow{3}{*}{ SF } & \multicolumn{10}{|c|}{ Pastejos } & \multirow{3}{*}{$\begin{array}{l}\mathrm{CV} \\
(\%)\end{array}$} \\
\hline & \multirow{2}{*}{$\frac{1^{\circ}}{\text { Jun/10 }}$} & \multirow{2}{*}{$\begin{array}{c}2^{\circ} \\
\text { Set/10 }\end{array}$} & \multirow{2}{*}{$\frac{3^{\circ}}{\text { Out/10 }}$} & \multirow{2}{*}{$\begin{array}{c}4^{\circ} \\
\text { Dez/10 }\end{array}$} & \multirow{2}{*}{$\frac{5^{\circ}}{\operatorname{Jan} / 11}$} & \multirow{2}{*}{$\frac{6^{\circ}}{\text { Fev/11 }}$} & \multirow{2}{*}{$\begin{array}{c}7^{\circ} \\
\text { Mar/11 }\end{array}$} & \multirow{2}{*}{$\frac{8^{\circ}}{\mathrm{Abr} / 11}$} & \multicolumn{2}{|c|}{ Produção } & \\
\hline & & & & & & & & & Média & Total & \\
\hline \multicolumn{11}{|c|}{ Produção de forragem do pasto } & \multirow{4}{*}{6,10} \\
\hline $\mathrm{SL}^{1}$ & 1,68 & 1,32 & 1,11 & 1,29 & $2,51 \mathrm{a}$ & 1,96 & 2,14 & $1,13 b$ & 1,10 & $13,14 b$ & \\
\hline $\mathrm{AM}^{2}$ & 1,97 & 1,81 & 1,14 & 1,32 & $2,40 \mathrm{~b}$ & 2,31 & 1,85 & $1,66 \mathrm{ab}$ & 1,21 & $14,46 a$ & \\
\hline $\mathrm{TV}^{3}$ & 2,18 & 1,45 & 1,00 & 1,72 & $2,05 \mathrm{~b}$ & 2,96 & 2,70 & $2,24 a$ & 1,36 & $16,30 \mathrm{a}$ & \\
\hline \multicolumn{11}{|c|}{ Capim elefante } & \multirow{4}{*}{10,03} \\
\hline SL & 0,99 & 0,58 & $*$ & 0,57 & 0,76 & 0,76 & 0,78 & 0,58 & 0,72 & 5,02 & \\
\hline $\mathrm{AM}$ & 1,21 & 0,83 & $*$ & 0,44 & 1,01 & 0,75 & 0,71 & 0,70 & 0,81 & 5,65 & \\
\hline TV & 1,23 & 0,69 & $*$ & 0,44 & 0,65 & 0,76 & 0,87 & 0,63 & 0,75 & 5,27 & \\
\hline \multicolumn{11}{|c|}{ Lâmina foliar de capim elefante } & \multirow{4}{*}{6,00} \\
\hline SL & 0,49 & 0,33 & $*$ & 0,48 & 0,68 & 0,54 & 0,69 & 0,44 & 0,52 & 3,63 & \\
\hline $\mathrm{AM}$ & 0,68 & 0,48 & $*$ & 0,35 & 0,81 & 0,66 & 0,64 & 0,58 & 0,60 & 4,19 & \\
\hline TV & 0,67 & 0,41 & $*$ & 0,36 & 0,46 & 0,65 & 0,85 & 0,52 & 0,56 & 3,90 & \\
\hline \multicolumn{11}{|c|}{ Colmo + bainha de capim elefante } & \multirow{4}{*}{10,88} \\
\hline SL & 0,50 & 0,25 & $*$ & 0,09 & 0,08 & 0,22 & 0,09 & 0,14 & 0,19 & 1,35 & \\
\hline $\mathrm{AM}$ & 0,53 & 0,35 & $*$ & 0,09 & 0,20 & 0,09 & 0,07 & 0,12 & 0,21 & 1,46 & \\
\hline TV & 0,56 & 0,28 & $*$ & 0,08 & 0,19 & 0,11 & 0,02 & 0,11 & 0,19 & 1,34 & \\
\hline \multicolumn{11}{|c|}{ Produção de forragem das entrelinhas de capim elefante } & \multirow{4}{*}{13,38} \\
\hline SL & 0,69 & 0,74 & 1,11 & 0,72 & 1,75 & $1,20 b$ & 1,36 & 0,55 & 1,02 & 8,12 & \\
\hline $\mathrm{AM}$ & 0,76 & 0,98 & 1,14 & 0,88 & 1,39 & $1,56 b$ & 1,14 & 0,96 & 1,10 & 8,81 & \\
\hline TV & 0,95 & 0,76 & 1,00 & 1,28 & 1,40 & $2,20 \mathrm{a}$ & 1,83 & 1,61 & 1,20 & 11,03 & \\
\hline \multicolumn{11}{|c|}{ Azevém } & \multirow{4}{*}{3,23} \\
\hline SL & 0,61 & 0,84 & 1,06 & - & - & - & - & - & 0,84 & 2,51 & \\
\hline $\mathrm{AM}$ & 0,56 & 0,58 & 0,79 & - & - & - & - & - & 0,64 & 1,93 & \\
\hline TV & 0,55 & 0,53 & 0,57 & - & - & - & - & - & 0,55 & 1,65 & \\
\hline \multicolumn{11}{|c|}{ Espécies de crescimento espontâneo } & \multirow{4}{*}{15,09} \\
\hline SL & 0,08 & 0,07 & 0,05 & 0,72 & $1,75 \mathrm{a}$ & $1,20 \mathrm{a}$ & $1,36 \mathrm{a}$ & $0,55 b$ & 0,72 & 5,78 & \\
\hline $\mathrm{AM}$ & 0,09 & 0,07 & 0,03 & 0,45 & $0,45 b$ & $0,57 b$ & $0,78 b$ & $0,45 b$ & 0,36 & 2,89 & \\
\hline TV & 0,06 & 0,06 & 0,05 & 0,20 & $0,31 b$ & $1,70 \mathrm{a}$ & $1,83 \mathrm{a}$ & $1,61 \mathrm{a}$ & 0,73 & 5,82 & \\
\hline & & & & & Legumi & osas & & & & & \\
\hline AM & $0,11 b$ & 0,33 & 0,32 & 0,43 & 0,94 & 0,99 & 0,36 & 0,51 & 0,50 & 3,98 & 1060 \\
\hline TV & $0,34 \mathrm{a}$ & 0,17 & 0,38 & 1,08 & 1,09 & 0,50 & - & - & 0,60 & 4,45 & 10,69 \\
\hline
\end{tabular}

${ }^{1} \mathrm{SL}=($ sem leguminosa) capim elefante $(\mathrm{CE})+$ azevém (AZE) + espécies de crescimento espontâneo (ECE), sem leguminosa; ${ }^{2} \mathrm{AM}=$ (consórcio com amendoim forrageiro) $\mathrm{CE}+\mathrm{AZE}+\mathrm{ECE}+$ amendoim forrageiro; ${ }^{3} \mathrm{TV}=($ consórcio com trevo vermelho $) \mathrm{CE}+\mathrm{AZE}+\mathrm{ECE}+$ trevo vermelho; *roçada das linhas constituídas pelas touceiras de capim elefante; - ausência do componente. Médias seguidas por letras distintas, na coluna, diferem entre si $(\mathrm{P} \leq 0,05)$. $\mathrm{CV}=$ coeficiente de variação. 
Para a taxa de acúmulo diário de matéria seca (Tab. 4), houve diferença nos pastejos efetuados em setembro com melhor resultado para o consórcio com amendoim forrageiro, apontando, assim, para o efeito residual dessa leguminosa, que, no período hibernal, tem parte de sua estrutura (folhas e nódulos) degradada pela ação das baixas temperaturas e das geadas, liberando nutrientes, especialmente $\mathrm{N}$, para o sistema (Wearner, 1988). As outras diferenças verificadas em fevereiro e abril devem-se ao ápice na produção de forragem que essa leguminosa atinge, contribuindo com as gramíneas associadas. Para a taxa de acúmulo de lâmina foliar do capim elefante, houve diferença com maior valor no consórcio com amendoim forrageiro, no pastejo efetuado em janeiro e no consórcio com trevo vermelho em março. Para as taxas de acúmulo diário de matéria seca das espécies de crescimento espontâneo, verificaramse maiores valores entre dezembro e abril, estando associadas à ausência de leguminosas; para as taxas das leguminosas, houve similaridade entre as espécies.

Tabela 4. Taxa de acúmulo diário de matéria seca (TAD), em kg/ha, de três sistemas forrageiros (SF). Santa Maria, RS

\begin{tabular}{|c|c|c|c|c|c|c|c|c|c|c|}
\hline \multirow{3}{*}{ SF } & \multicolumn{8}{|c|}{ Pastejos } & \multirow{3}{*}{ Média } & \multirow{3}{*}{$\begin{array}{l}\text { CV } \\
(\%)\end{array}$} \\
\hline & $1^{\circ}$ & $2^{\circ}$ & $3^{\circ}$ & $4^{\circ}$ & $5^{\circ}$ & $6^{\circ}$ & $7^{\circ}$ & $8^{\circ}$ & & \\
\hline & Jun/10 & Set/10 & Out/10 & Dez/10 & $\mathrm{Jan} / 11$ & Fev/11 & Mar/11 & $\mathrm{Abr} / 11$ & & \\
\hline \multicolumn{11}{|c|}{ TAD do pasto } \\
\hline $\mathrm{SL}^{1}$ & 40,47 & $37,05 b$ & 27,63 & 17,36 & 68,47 & $69,86 b$ & 67,10 & $36,12 \mathrm{c}$ & 48,00 & \multirow{3}{*}{15,95} \\
\hline $\mathrm{AM}^{2}$ & 45,00 & $45,08 \mathrm{a}$ & 28,30 & 17,84 & 79,90 & $82,54 a$ & 59,74 & $53,47 b$ & 54,34 & \\
\hline $\mathrm{TV}^{3}$ & 49,62 & $35,93 b$ & 25,30 & 23,53 & 68,50 & $80,61 \mathrm{a}$ & 66,74 & $72,19 a$ & 55,43 & \\
\hline \multicolumn{11}{|c|}{ TAD de capim elefante } \\
\hline SL & 22,00 & $14,30 \mathrm{~b}$ & - & 7,68 & $25,13 \mathrm{ab}$ & 26,89 & 25,16 & 18,50 & 19,95 & \multirow{3}{*}{6,17} \\
\hline $\mathrm{AM}$ & 26,98 & $20,75 a$ & - & 5,86 & $33,87 \mathrm{a}$ & 27,04 & 22,90 & 22,35 & 22,82 & \\
\hline TV & 27,20 & $17,05 \mathrm{~b}$ & - & 5,93 & $21,70 \mathrm{~b}$ & 26,82 & 28,03 & 20,19 & 20,99 & \\
\hline \multicolumn{11}{|c|}{ TAD de lâmina foliar do capim elefante } \\
\hline SL & 10,93 & 8,18 & $*$ & 6,42 & $22,63 \mathrm{ab}$ & 19,21 & $22,19 b$ & 14,73 & 14,81 & \multirow{3}{*}{13,99} \\
\hline $\mathrm{AM}$ & 15,13 & 11,91 & $*$ & 4,66 & $27,07 \mathrm{a}$ & 23,61 & $20,58 b$ & 18,58 & 17,36 & \\
\hline TV & 14,79 & 10,19 & $*$ & 4,85 & $15,23 b$ & 23,04 & $27,35 \mathrm{a}$ & 16,74 & 16,03 & \\
\hline \multicolumn{11}{|c|}{ TAD de colmo + bainha do capim elefante } \\
\hline SL & 11,07 & 6,13 & $*$ & 1,26 & 2,50 & 7,68 & 2,97 & 4,37 & 5,14 & \multirow{3}{*}{12,35} \\
\hline $\mathrm{AM}$ & 11,84 & 8,85 & $*$ & 1,20 & 6,80 & 3,43 & 2,32 & 3,76 & 5,46 & \\
\hline TV & 12,40 & 6,88 & $*$ & 1,08 & 6,47 & 3,79 & 0,68 & 3,45 & 4,96 & \\
\hline \multicolumn{11}{|c|}{ TAD da forragem presente entre as linhas do capim elefante } \\
\hline SL & 18,47 & 22,75 & 27,63 & $9,69 b$ & 43,33 & $42,96 b$ & $41,94 \mathrm{a}$ & $17,61 \mathrm{c}$ & 28,05 & \multirow{3}{*}{17,75} \\
\hline $\mathrm{AM}$ & 18,02 & 24,33 & 28,30 & $11,97 b$ & 46,03 & $55,50 \mathrm{a}$ & $36,84 b$ & $31,13 b$ & 31,52 & \\
\hline TV & 22,42 & 18,88 & 25,30 & $17,59 \mathrm{a}$ & 46,80 & $53,79 \mathrm{a}$ & $38,71 b$ & $52,00 \mathrm{a}$ & 34,41 & \\
\hline \multicolumn{11}{|c|}{ TAD do azevém } \\
\hline SL & 13,56 & 21,05 & 26,48 & - & - & - & - & - & 20,36 & \multirow{3}{*}{16,91} \\
\hline $\mathrm{AM}$ & 12,51 & 14,40 & 19,60 & - & - & - & - & - & 15,51 & \\
\hline TV & 12,33 & 13,23 & 14,35 & - & - & - & - & - & 13,30 & \\
\hline \multicolumn{11}{|c|}{ TAD das espécies de crescimento espontâneo } \\
\hline SL & 4,91 & 1,70 & 1,15 & 9,69 & $43,33 \mathrm{a}$ & $42,96 a$ & $41,94 a$ & $17,61 b$ & 20,41 & \multirow{3}{*}{14,79} \\
\hline $\mathrm{AM}$ & 3,16 & 1,75 & 0,70 & 6,11 & $14,87 \mathrm{~b}$ & $20,29 b$ & $25,23 b$ & $14,72 b$ & 10,85 & \\
\hline TV & 2,53 & 1,45 & 1,38 & 2,97 & $10,50 b$ & $35,71 \mathrm{a}$ & $38,71 \mathrm{a}$ & $52,00 \mathrm{a}$ & 18,16 & \\
\hline \multicolumn{10}{|c|}{ TAD das leguminosas } & \\
\hline $\mathrm{AM}$ & $2,36 b$ & 8,18 & 8,00 & 5,86 & 31,17 & 35,21 & 11,61 & 16,42 & 14,85 & \multirow{2}{*}{11,60} \\
\hline $\mathrm{TV}$ & $7,56 \mathrm{a}$ & 4,20 & 9,58 & 14,62 & 36,30 & 18,07 & - & - & 15,05 & \\
\hline
\end{tabular}

${ }^{1} \mathrm{SL}=($ sem leguminosa) capim elefante $(\mathrm{CE})+$ azevém (AZE) + espécies de crescimento espontâneo (ECE), sem leguminosa; ${ }^{2} \mathrm{AM}=$ (consórcio com amendoim forrageiro) $\mathrm{CE}+\mathrm{AZE}+\mathrm{ECE}+$ amendoim forrageiro; ${ }^{3} \mathrm{TV}=$ (consórcio com trevo vermelho) CE + AZE + ECE + trevo vermelho; *roçada das linhas constituídas pelas touceiras de capim elefante; - ausência do componente. Médias seguidas por letras distintas, na coluna, diferem entre si $(\mathrm{P} \leq 0,05)$. $\mathrm{CV}=$ coeficiente de variação. 


\section{CONCLUSÕES}

Sistemas forrageiros que envolvem gramíneas e leguminosas de diferentes ciclos de produção proporcionam a utilização da área durante todo o ano agrícola em pastejo rotativo com bovinos leiteiros. Considerando-se a predominância das avaliações em cada pastejo, os sistemas forrageiros consorciados apresentam melhor resultados tanto paras as variáveis de massa de forragem quanto para a taxa de lotação. Nos consórcios, verifica-se melhor distribuição da forragem produzida. As leguminosas interferem no desenvolvimento das espécies de crescimento espontâneo, diminuindo sua produção de forragem.

\section{REFERÊNCIAS}

ASSIS, G.M.L.; VALENTIM, J.F.; CARNEIRO JÚNIOR, J.M. et al. Seleção de genótipos de amendoim forrageiro para cobertura do solo e produção de biomassa aérea no período de estabelecimento utilizando-se metodologia de modelos mistos. Rev. Bras. Zootec., v.37, p.1905-1911, 2008.

AZEVEDO JUNIOR, R.L. Produtividade $e$ composição química de forragem de amendoim forrageiro e trevo vermelho consorciadas com gramíneas. 2011. 90f. Dissertação (Mestrado em Zootecnia) - Universidade Federal de Santa Maria, Santa Maria, 2011.

BARCELLOS, A.O.; RAMOS, A.K.B.; VILELA, L. et al. Sustentabilidade da produção animal baseada em pastagens consorciadas e no emprego de leguminosas exclusivas, na forma de banco de proteína, nos trópicos brasileiros. Rev. Bras. Zootec., v.37, p.51-67, 2008.

CADISH, G.; SCHUNKE, R.M.; GILLER, K.E. Nitrogen cycling in a pure grass pasture and a grass-legume misture on a red latosol in Brazil. Trop. Grassl., v.28, p.43-52, 1994.

COMISSÃO DE QUÍMICA E FERTILIDADE DO SOLO - RS/SC. Manual de adubação $e$ calagem para os estados do Rio Grande do Sul e Santa Catarina. Porto Alegre: SBCSNRS, 2004. 400p.
DERESZ, F. Produção de leite de vacas mestiças holandês $\mathrm{x}$ zebu em pastagem de capim elefante manejadas em sistema de pastejo rotativo com e sem suplementação durante a época das chuvas. Rev. Bras. Zootec., v.30, p.197-204, 2001.

EMBRAPA - EMPRESA BRASILEIRA DE PESQUISA EM AGROPECUÁRIA. Centro Nacional e Pesquisa em Solos. Sistema Brasileiro de Classificação de Solos. Brasília: Embrapa-SPI; Rio de Janeiro: Embrapa-Solos, 2006. 306p.

LIMA, M.L.P.; BERCHIELLI, T.T.; LEME, P.R. et al. Concentração de nitrogênio ureico plasmático (nup) e produção de leite de vacas mestiças mantidas em gramíneas tropicais sob pastejo rotacionado. Rev. Bras. Zootec., v.33, p.1616-1626, 2004.

MORENO, J.A. Clima do Rio Grande do Sul. Porto Alegre: Secretaria da Agricultura, 1961. $41 \mathrm{p}$.

OLIVO, C.J.; ZIECH, M.F.; BOTH, J.F. et al. Produção de forragem e carga animal em pastagens de capim elefante consorciadas com azevém, espécies de crescimento espontâneo e trevo branco ou amendoim forrageiro. Rev. Bras. Zootec., v.38, p.27-33, 2009.

PAIM, N.R. Manejo de leguminosas de clima temperado. In: SIMPÓSIO SOBRE MANEJO DE PASTAGEM, 9., 1998, Piracicaba. Anais... Piracicaba: FEALQ, 1998. p.341-358.

PAULINO, V.T.; BRAGA, G.J.; LUCENA, M.A.C. et al. Sustentabilidade de pastagens consorciadas - ênfase em leguminosas forrageiras. In: PAULINO, V.T.; BRAGA, G.J.; LUCENA, M.A.C. et al. (Org.). II Encontro Sobre Leguminosas Forrageiras. 1.ed. Nova Odessa: IZ/APTA/SAA, 2008, v.1, p.1-55.

PEREIRA, J.M. Produção e persistência de leguminosas em pastagens tropicais. In: SIMPÓSIO DE FORRAGICULTURA E PASTAGENS, 2., 2001, Lavras. Anais... Lavras: UFLA, 2001. p.111-142.

RESTlE, J.; ROSO, C.; AITA, V. et al. Produção animal em pastagem com gramíneas de estação quente. Rev. Bras. de Zootec., v.31, p.1491-1500, 2002. 
ROCHA, M.G.; PEREIRA, L.E.T.; SCARAVELLI, L.F.B. et al. Produção e qualidade de forragem da mistura de aveia e azevém sob dois métodos de estabelecimento. Rev. Bras. Zootec., v.36, p.715, 2007.

SILVA, D.J. Análise de alimentos (métodos químicos e biológicos). Viçosa: UFV, Impr. Univ., 1990. 165p.

SILVA, S.C. Desafios e perspectivas para a pesquisa e uso de leguminosas em pastagens tropicais: uma reflexão. In: ENCONTRO TÉCNICO SOBRE LEGUMINOSAS, 2., 2008, Nova Odessa. Anais... Nova Odessa: Instituto de Zootecnia, 2008. p.163-168.

SHONIESKI, F.R.; VIÉGAS, J.; BERMUDES, R.F. et al. Composição botânica e estrutural e valor nutritivo de pastagens de azevém consorciadas. Rev. Bras. Zootec., v.40, p.550556, 2011.

STATISTICAL Analysis Sistem. Sas Institute, SAS, Statistical analysis user's guide. Version 8.2, Cary: SAS Institute, 2001. 1686 p.

STEINWANDTER, E.; OLIVO, C.J.; SANTOS, J.C. et al. Produção de forragem em pastagens consorciadas com diferentes leguminosas sob pastejo rotacionado. Acta Scient. Anim. Sci., v.31, p.131-137, 2009.
TEODORO, R.B.; OLIVEIRA, F.L.; SILVA, D.M.N. et al. Eficiência de leguminosas utilizadas na adubação verde no controle de plantas espontâneas. In: CONGRESSO BRASILEIRO DA CIÊNCIA DAS PLANTAS DANINHAS, 27., 2010, Ribeirão Preto. Anais... Ribeirão Preto, 2010. Disponível em <http://www.sbcpd.org/portal/anais/XXVII_CBC PD/PDFs/233.pdf>. Acessado em: 24 jan. 2012.

THOMAS, R.J. The role of the legume in the nitrogen cycle of productive and sustainable pastures. Grass and For. Sci., v.47, p.133-142, 1992.

WEARNER, R.W. Isotope dilution as a method for measuring nitrogen transfer from forage legumes to grass. In: BECK, D.P.; MATERON, L.A. Nitrogen fixation by legumes in mediterranean agriculture. Netherlands: ICARDA, 1988. p.358365.

WILM, H.G.; COSTELO, D.F.; KLIPPLE, G.E. Estimating forage yield by the double sampling method. J. Am. Soc. Agron., v.36, p.194-203, 1944. 